\title{
SCIENTIFIC REPORTS

\section{Fabrication of functionalized electrospun carbon nanofibers for enhancing lead-ion adsorption from aqueous solutions}

\author{
Badr M. Thamer ${ }^{1}$, Ali Aldalbahi ${ }^{1}$, Meera Moydeen A $^{1}$, Abdullah M. Al-Enizi ${ }^{1}$, \\ Hany El-Hamshary ${ }^{1,2}$ \& Mohamed H. El-Newehy ${ }^{1,2^{2 *}}$
}

Electrospinning technique is a simple and cheap method for fabrication of electrospun nanofibers (ENFs), which in turn can converted into electrospun carbon nanofibers (ECNFs) by carbonization process. The controlling of the ECNFs properties (e.g. surface area, porosity, diameters) during fabrication, make it superior over the other carbon nanomaterials. The aim of our study is to modify the surface of ECNFs to increase its hydrophilicity and in turn its efficiency in removing lead ions $\left(\mathrm{Pb}^{2+}\right)$ from aqueous systems. The surface modification was carried out in two steps starting from oxidation of pristine ECNFs to produce oxidized ECNFs (o-ECNFs), followed by covalently bonded of melamine, and poly ( $m$-phenylene diamine) for forming melamine-functionalized ECNFs (melam-ECNFs) and poly $(m$ phenylene diamine)-functionalized ECNFs (PmPDA-ECNFs), respectively. The as-prepared materials were characterized in routine way. The ability of the as-prepared materials towards adsorption of $\mathrm{Pb}^{2+}$ ions as heavy metal was investigated with the study of some factors such as $\mathrm{pH}$ solution, contact time, initial concentration and temperature. The adsorption process was analyzed isothermally, and kinetically. According to the values of the thermodynamic parameters, the adsorption of $\mathrm{Pb}^{2+}$ ions onto the functionalized ECNFs was endothermic and spontaneous, except with melam-ECNFs was exothermic.

Environmental pollution with heavy metals is a major challenge at present and for the future. The continuation of this challenge lies in the dependence of many industries on these metals, as well as their accumulation in nature and their non-degradability ${ }^{1}$. Among toxic metals, the lead ion $\left(\mathrm{Pb}^{+2}\right)$ is one of the most hazardous metals in the category of priority pollutants. The transfer of lead ions to organisms through the food chain can cause serious health problems (e.g., mental retardation, anemia, and kidney disease) owing to their accumulation and the inability of the body to eliminate them ${ }^{2}$. The maximum concentration of lead ions $\left(\mathrm{Pb}^{2+}\right)$ in public drinking water is $15 \mu \mathrm{g} / \mathrm{L}$, according to a report of the US Environmental Protection Agency ${ }^{3}$. Thus, lead ions should be removed from wastewater to avoid prospective hazards to environment and humans. Many techniques have been used to remove lead ions and other metal ions from aqueous solutions and wastewater, including filtration, precipitation, ion exchange, and adsorption ${ }^{4}$. Adsorption is one of the most favorable and economical techniques for removing toxic metals and other chemical contaminants from wastewater ${ }^{5}$. Therefore, the synthesis of new, effective, and economical adsorbent materials has been the goal of many researchers in the field of water treatment ${ }^{6}$.

Fibrous nanomaterials (FNMs) have received considerable attention in industrial and academic fields owing to their unique properties and possibility for large-scale production ${ }^{7,8}$. The large surface area, low density, highly porous structure, and distinctive mechanical properties of FNMs make them promising materials for many applications, such as filtration, scaffolds in tissue engineering, drug delivery, energy conversion, and environmental applications ${ }^{9-11}$. Recently, FNMs have been widely applied as nanoadsorbents for the removal of various pollutants from aqueous systems owing to their distinctive properties. Generally, FNMs are categorized into several types according to their composition: polymeric nanofibers, carbon nanofibers, inorganic nanofibers, and composite nanofibers. There are many techniques of producing FNMs, but the electrospinning is the most common technique for producing electrospun carbon nanofibers (ECNFs) because it is easy, simple, inexpensive 
and allows the large-scale production of fibers with multiple morphological ${ }^{12-14}$. ECNFs have been attracted considerable attention as efficient adsorbents for the removal of pollutants owing to their high surface-to-volume ratio and their ability to establish $\pi-\pi$ electrostatic interactions. ECNFs have exhibited good adsorption capabilities for various nonpolar pollutants, such as toluene, benzene, and mineral oils ${ }^{15-17}$. However, pristine ECNFs as adsorbents is ineffective for the removal of ionic pollutants from aqueous systems because of their hydrophobic nature and the strong intermolecular interactions (Van der Waals forces) between the fibers, which could reduce the dispersion and lead to the formation of aggregates. A common technique for increasing the adsorption capacity of carbon nanomaterials is surface modification, which generates functional groups on their surface and enhances the hydrophilicity ${ }^{18}$. Previous studies indicated that the surface of ECNFs can be chemically modified to improve porosity and produce various functional groups that in turn improves their ability to remove ionic contaminants ${ }^{19-21}$. Many oxygen functional groups, hydroxyl groups $(-\mathrm{OH})$, and carboxylic groups $(-\mathrm{COOH})$ can be created simultaneously onto the fiber surface via chemical activation ${ }^{19,22,23}$. Owing to the reactivity of carboxylic groups with many other functional materials (e.g. diamines and polymers), they play as active points for further organic functionalization, as well as enhancing dispersion property and adsorption capacities of carbon nanomaterials ${ }^{24-26}$. Most of the previous studies were limited to modifying the surface of ECNFs using acidic or alkali agents, and did not yet focus on their organic functionalization ${ }^{27}$. Although these studies have indicated the effectiveness of activated ECNFs for the removal of ionic pollutants such as dyes ${ }^{28,29}$, but have not been utilized to remove toxic metals. The surface modification of ECNFs has the potential for improving their properties, and making those promising candidates for various applications, including heavy metals removal. Amino modification is a widely used method to produce nitrogen containing functional groups (e.g. $-\mathrm{C}-\mathrm{N},-\mathrm{C}=\mathrm{N},-\mathrm{NH}$, $-\mathrm{NH}_{2}$ ) onto the surface of carbon nanomaterials, which can enhance their adsorption efficiency towards heavy metal ions removal ${ }^{30}$. Melamine and polyphenylene diamine are one of the amino reagents containing rich amino groups that can covalently bind to the surface of carbon materials and enhancing their efficiency in adsorption of lead ions ${ }^{31,32}$.

Herein, we report the first study on the preparation of amine-functionalized ECNFs and their use for removing $\mathrm{Pb}^{2+}$ ions from aqueous solutions. The prepared materials were achieved via electrospinning, thermal treatment, and acid treatment, followed by an amine organic functionalization process. The utilization of pristine, oxidized, and functionalized ECNFs for the removal of $\mathrm{Pb}^{2+}$ ions from an aqueous solution and the adsorption mechanism were investigated via isotherm, kinetic, and thermodynamic analyses.

\section{Results and Discussion}

Characterization of adsorbents. FESEM images of pristine and functionalized ECNFs are shown in Fig. 1. The pristine ECNFs kept its morphology with a smooth surface, and average fiber diameter of $229.3 \mathrm{~nm}$ (Fig. 1a). Upon oxidation, the surface of the o-ECNFs became rougher, as the acid treatment caused structural defects and created functional groups, which were expected to increase the amount of active sites and promote adsorption (Fig. 1b). The roughness increased with melam-ECNFs and the fiber diameter became larger $(252 \mathrm{~nm})$ due to the surface functionalization with melamine (Fig. 1c). After functionalization with PmPDA, nanoparticles were observed onto the surface of PmPDA-ECNF nanocomposites, confirming the successfully grafting of P $m$ PDA onto the surface of the ECNFs (Fig. 1d). In general, compared with the pristine ECNFs, the structure of the functionalized ECNFs was partially broken, but their nanomorphologies were preserved.

The new functional groups appeared on the surface of functionalized ECNFs were affirmed by FT-IR spectroscopy, as displayed in Fig. 2. The FT-IR spectrum of pristine ECNFs exhibited characteristic absorption peaks at $1563 \mathrm{~cm}^{-1}(\mathrm{C}=\mathrm{C}$ stretching from aromatic system $)$ and $1174 \mathrm{~cm}^{-1}(\mathrm{C}-\mathrm{N}$ stretching vibration). The successful functionalization of the oxygenated functional groups onto the o-ECNFs surface was also confirmed by the new peaks at 3395 and $1709 \mathrm{~cm}^{-1}$, which were attributed to hydroxyl groups and carbonyl-carboxylic groups, respectively. The spectrum of the melam-ECNFs exhibited the disappearance of the absorption band of the carbonyl-carboxylic groups at $1709 \mathrm{~cm}^{-1}$ and the appearance of a new sharp peak at $1590 \mathrm{~cm}^{-1}$, which was ascribed to the formation of carbonyl-amide groups. Additionally, two new peaks observed at 1350 and $787.5 \mathrm{~cm}^{-1}$ due to the stretching frequencies and the out-of-plane bending modes of the triazine ring, respectively ${ }^{33}$. This confirms the grafting of melamine molecules onto the surface of the o-ECNFs via the creation of amide bonds. For PmPDA-ECNFs, new peaks appeared at 1617,1364 and $1295 \mathrm{~cm}^{-1}$, which may be assigned to the stretching vibration of quinoid rings and benzenoid and quinoid imine units in poly $\left(m\right.$-phenylene diamine), respectively ${ }^{34}$. Moreover, the absorption peak of the carbonyl-carboxylic group at $1709 \mathrm{~cm}^{-1}$ was shifted to $1617 \mathrm{~cm}^{-1}$ owing to its conversion into carbonyl-amide group. The absorption peak of the amide group overlapped with that of the quinoid rings. Thus, it can be inferred that PmPDA was successfully grafted onto the ECNFs.

XPS spectra (wide range scan) of melam-ECNFs and P $m$ PDA-ECNFs and high resolution spectra with the deconvolution for their relevant C1s, N1s and O1s are shown in Figs. 3 and 4. As displayed in Figs. 3a and 4a, the wide range scan reveals three distinct and sharp peaks at $\mathrm{C} 1 \mathrm{~s} / \sim 284.5 \mathrm{eV}, \mathrm{N} 1 \mathrm{~s} / \sim 399 \mathrm{eV}$ and $\mathrm{O} 1 \mathrm{~s} / \sim 532 \mathrm{eV}$ which indicated that the melam-ECNFs and P $m$ PDA-ECNFs contained three elements: carbon, nitrogen and oxygen. The appearance of a nitrogen peak in both spectra is a physical evidence of successful functionalization process onto surface of ECNFs by melamine and PmPDA. To determine the nature of the functional groups associated with the surface of ECNFs after functionalization, deconvolutions of C $1 \mathrm{~s}, \mathrm{~N} 1 \mathrm{~s}$ and $\mathrm{O} 1 \mathrm{~s}$ were performed. The spectra of C $1 \mathrm{~s}$ for melam-ECNFs exhibits several peaks at 284.35, 284.87, 285.2, 285.9, 287.5 and $288.4 \mathrm{eV}$ which attributed to $\mathrm{C}=\mathrm{C}, \mathrm{C}-\mathrm{C}, \mathrm{C}-\mathrm{N}, \mathrm{C}-\mathrm{O}, \mathrm{C}=\mathrm{O}$ and $\mathrm{N}-\mathrm{C}=\mathrm{O}$, respectively ${ }^{35}$. Although the peak of $\mathrm{C}=\mathrm{C}(284.35 \mathrm{eV})$ is predominant, the appearance of other peaks confirms that the surface of mealm-ECNFs contains oxygen and nitrogen functional groups.

The $\mathrm{N} 1 \mathrm{~s}$ spectra shows the nitrogen takes many forms according to the nature of nitrogen functional groups that bonding with surface of ECNFs as shown in Fig. 3c. The main peak is located at $399 \mathrm{eV}$ which is attributed to $\mathrm{C}=\mathrm{N}-\mathrm{C}$ that form melamine structure ${ }^{36}$. Two peaks in spectra of $\mathrm{O} 1 \mathrm{~s}$ with a binding energy of 530.6 and 

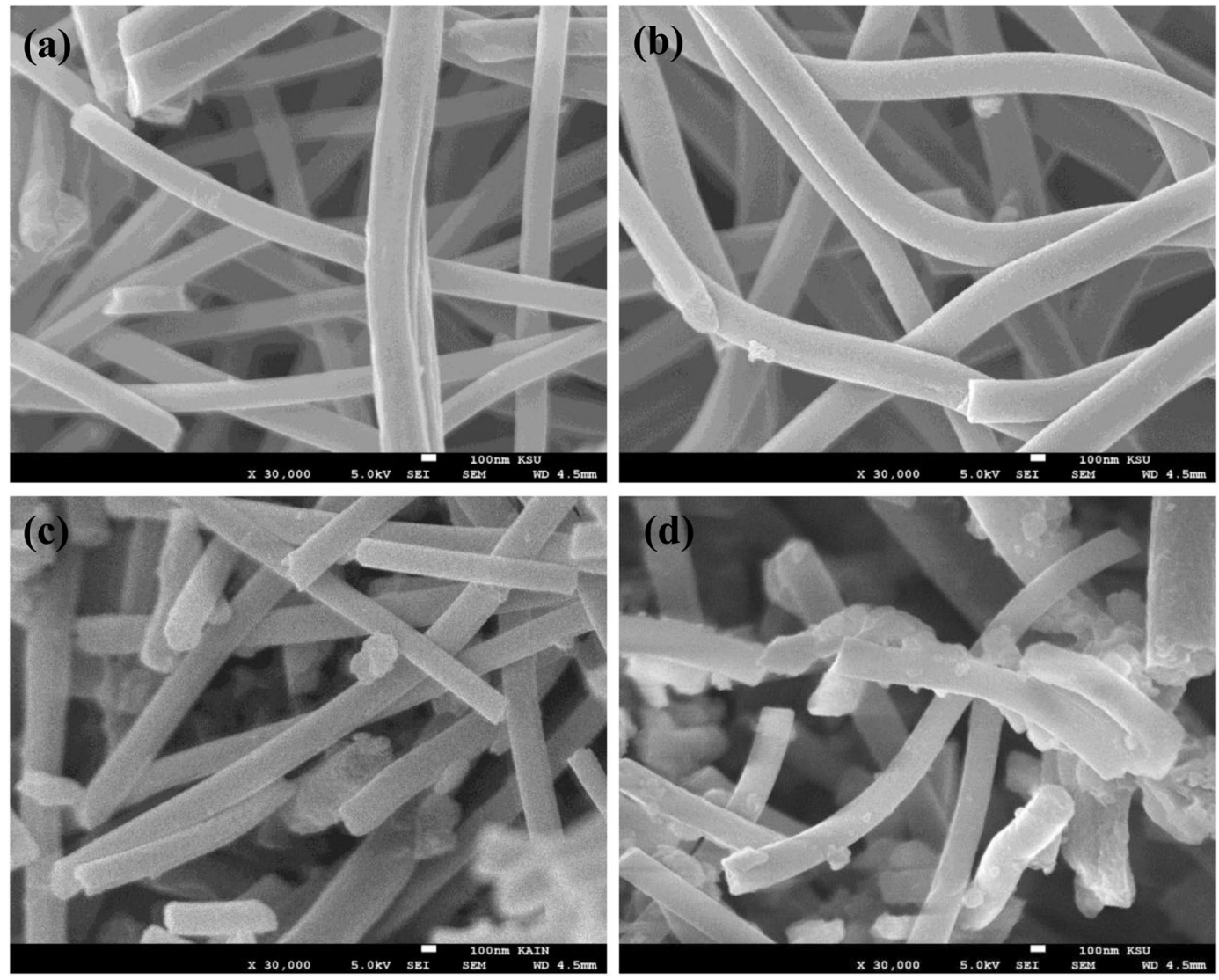

Figure 1. SEM image of ECNFs (a), o-ECNFs (b), melam-ECNFs (c), and PmPDA-ECNFs (d).

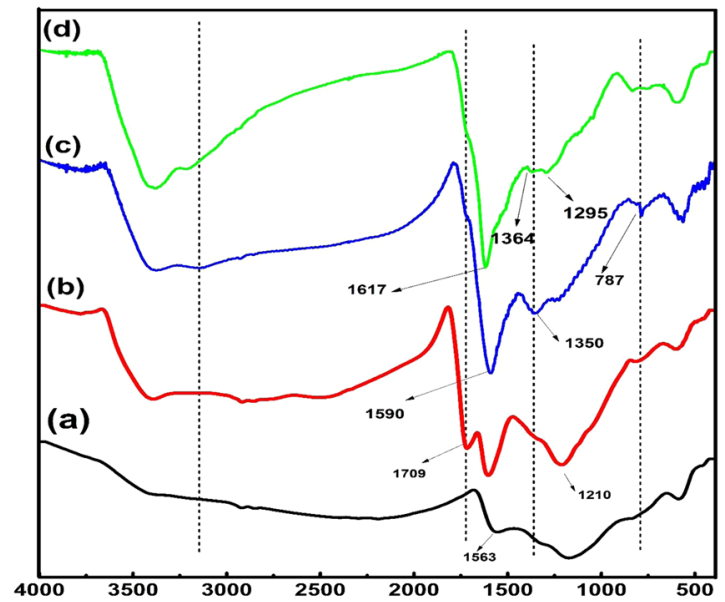

Figure 2. FTIR spectrum of ECNFs (a), o-ECNFs (b), melam-ECNFs (c), and PmPDA-ECNFs (d).

$532.4 \mathrm{eV}$ in Fig. $3 \mathrm{~d}$ are assigned to the $\mathrm{O}=\mathrm{C}-\mathrm{OH}$ and $\mathrm{C}-\mathrm{O}-\mathrm{H}$, respectively. For $\mathrm{P} m \mathrm{PDA}-\mathrm{ECNF}$, the deconvolution analysis shows significant peaks at $284.1(\mathrm{C}=\mathrm{C})$ and $285.5(\mathrm{C}-\mathrm{OH}) \mathrm{eV}$ for $\mathrm{C} 1 \mathrm{~s}, 398.6(\mathrm{C}=\mathrm{N}-)$ and $400.7 \mathrm{eV}$ (graphitic N) for $\mathrm{N} 1 \mathrm{~s}$ and $530.7(\mathrm{C}-\mathrm{OH})$ and $531.9 \mathrm{eV}(\mathrm{C}=\mathrm{O})$ for $\mathrm{O} 1 \mathrm{~s}$ as shown in Fig. $4(\mathrm{~b}-\mathrm{d})^{37}$. Based on the XPS analysis, the hydrophilicity of the functionalized ECNFs could be attributed to the presence of oxygen and nitrogen functional groups on their surface.

For further investigation of the grafting process on the surface of the ECNFs, TGA was performed under $\mathrm{N}_{2}$ gas as shown in Fig. 5. The residual weight percentage of pristine ECNFs at $600{ }^{\circ} \mathrm{C}$ was $96 \%$, indicating its high thermal stability. After surface modification, the thermal stability differed substantially, and the residual weight percentages of o-ECNFs, melam-ECNFs, and PmPDA-ECNFs at $600{ }^{\circ} \mathrm{C}$ were $74 \%, 78 \%$, and $75 \%$, respectively. As shown in Fig. 5, the weight loss of the o-ECNFs at $120^{\circ} \mathrm{C}$ is approximately $5.0 \%$, which may be ascribed 

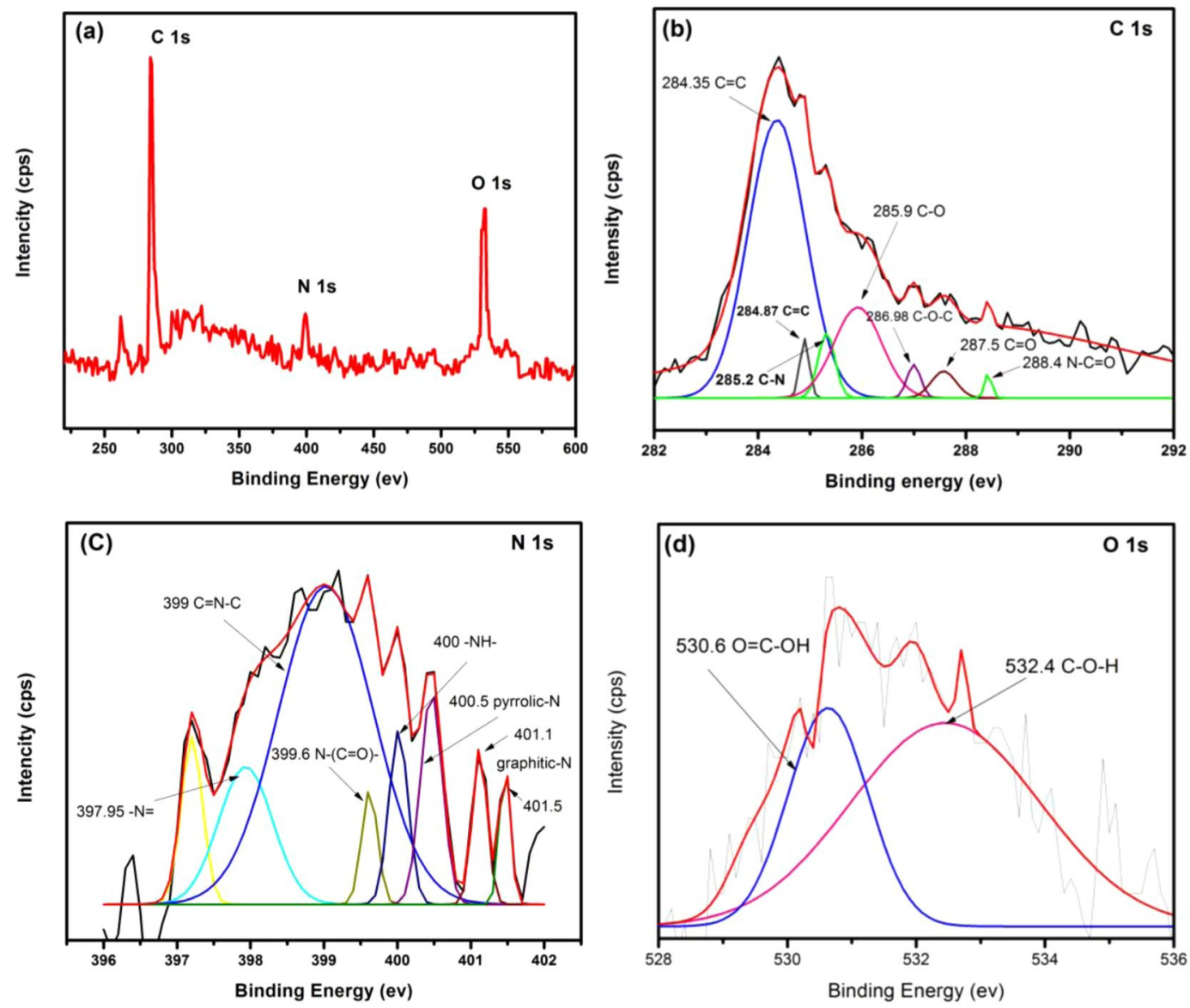

Figure 3. XPS spectra of melam-ECNFs.

to the evaporating moisture. The major steps of the weight loss of o-ECNFs occurred within the temperature ranges of $130-410$ and $420-600{ }^{\circ} \mathrm{C}$ which may be assigned to the removing of oxygen functional groups ${ }^{27}$. The melam-ECNFs showed different thermal decomposition behavior and high stability compared to o-ECNFs. Thermal degradation process of melam-ECNFs was occurred in three steps. The first step started below $120^{\circ} \mathrm{C}$ due to the evaporation of physically adsorbed water. The second step was occurred at $210-360^{\circ} \mathrm{C}$ which attributed to the degradation of oxygen functional groups $(\mathrm{OH}$ and $\mathrm{COOH})$. The final step was occurred over $500^{\circ} \mathrm{C}$ which may be assigned to the decomposition of melamine and intermediate compounds. The P $m$ PDA-ECNFs showed more stability than o-ECNFs and was degraded in three steps. The first degradation observed at $30-130^{\circ} \mathrm{C}$ was mainly due to the evaporation of water molecules and the second degradation was observed at $130-230^{\circ} \mathrm{C}$ was due to the deprotonation of polymeric chains which may lead to the losing of dopant $\mathrm{HCl}^{34}$. The third degradation observed beyond at $600^{\circ} \mathrm{C}$ was attributed to the degradation of polymer chains. The significant differences in thermal behavior clearly confirmed the surface modification of ECNFs achieved by the oxidation and grafting process.

The surface area and pore volume of ECNFs, o-ECNFs and PmPDA-ECNFs are listed in Table S1. The surface area of P $m$ PDA-ECNFs is evidently lower than the o-ECNFs. This may be due to the blocking of pores upon grafting with PmPDA, which in turn decreases the surface area of the ECNFs. On the other hand, the functionalization of ECNFs with melamine and P $m$ PDA plays an important role in enhancement of the adsorption capacity which is not depend only from the surface area.

The study of the change in the crystalline structure of carbon materials via XRD is useful for confirming surface modification. As shown in Fig. 6, the XDR spectrum of the pristine ECNFs exhibited a main peak at $24.4^{\circ}$ and a weak peak at $44.1^{\circ}$, which are related to the pseudo-graphite structure and the turbostratic carbon structure, respectively. After functionalization, the intensity of the main peak decreased, and the diffraction angle of the peak increased. The average interlayer spacing $\left(d_{002}\right)$ of the ECNFs was $0.364 \mathrm{~nm}$, which was calculated using Bragg's equation. After functionalization, the o-ECNFs, melam-ECNFs, and P $m$ PDA-ECNFs exhibited gradually decreasing with brooding of peaks and reducing in the average $d_{002}$ values, which were calculated as $0.361,0.359$, and $0.353 \mathrm{~nm}$, respectively. The decreasing and widened graphitic peak of the functionalized ECNFs is attributed to a breakdown in the graphitic lattice structure. Moreover, the spectrum of the melam-ECNFs exhibited a new peak at $18.08^{\circ}$, which corresponds to the triazine unit ${ }^{38}$. In general, the weaker diffraction peaks for functionalized ECNFs are due to the lower-order structure of the carbon fiber graphite layers, which confirms the successful modification of the fiber surface. 

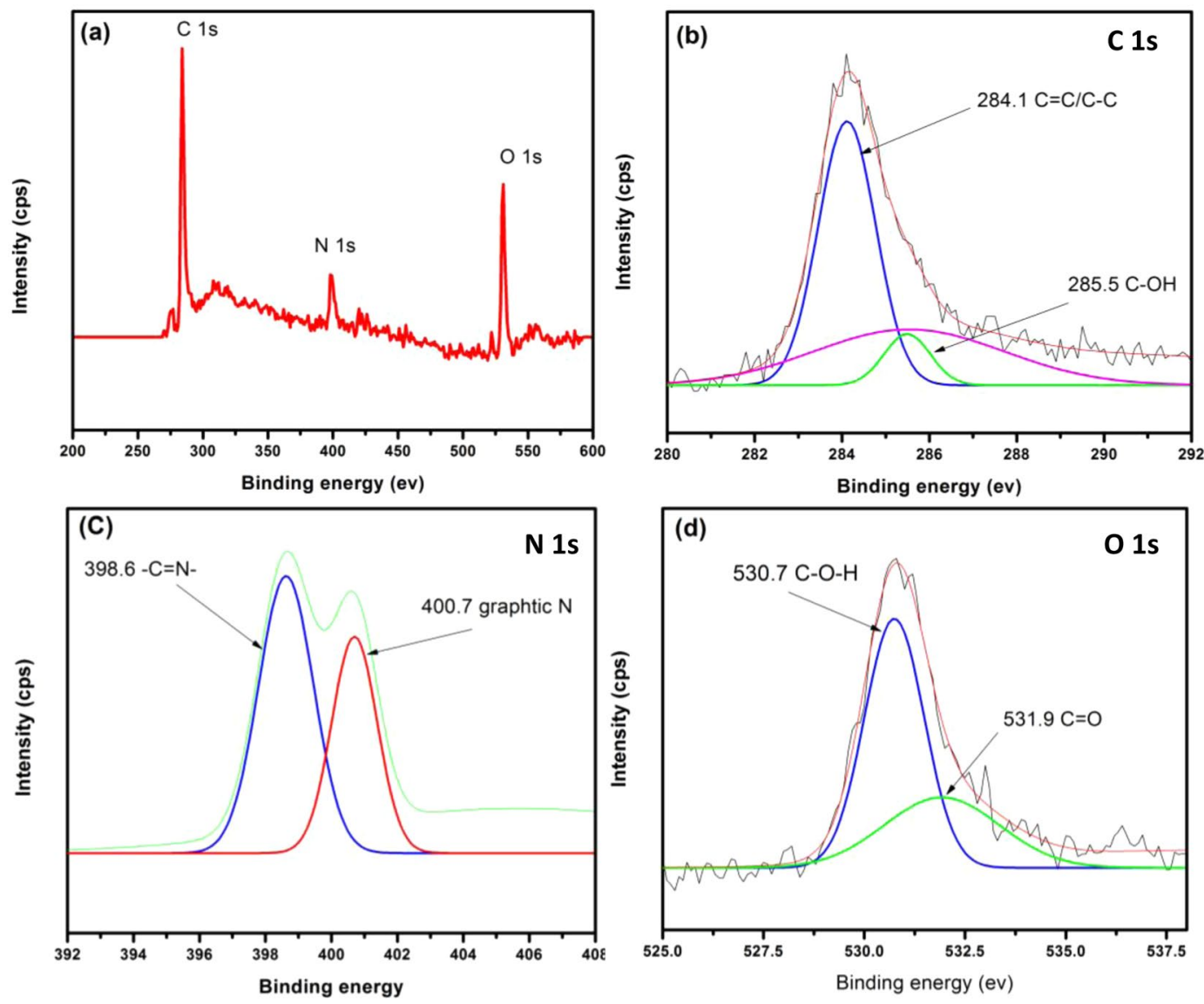

Figure 4. XPS spectra of PmPDA-ECNFs.

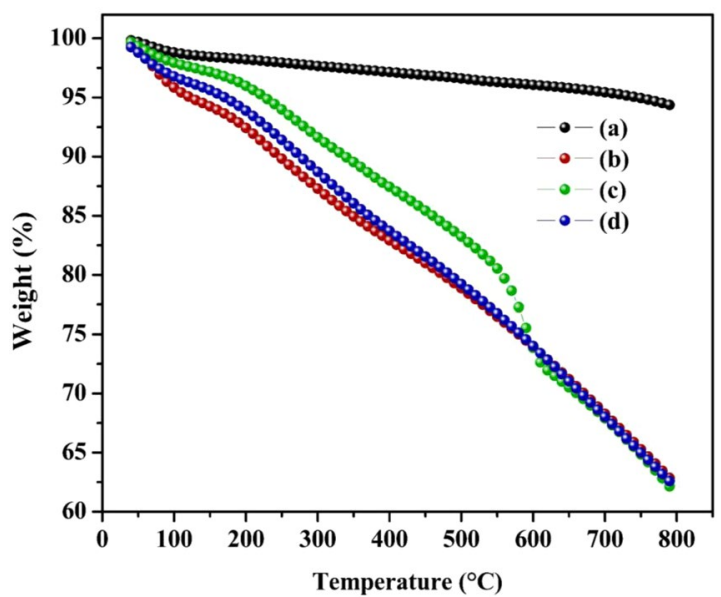

Figure 5. TGA thermogram of ECNFs (a), o-ECNFs (b), melam-ECNFs (c) and PmPDA-ECNFs (d).

Adsorption study. Effect of $p H$. The $\mathrm{pH}$ has a significant influence on the adsorption process because of its effects on both the adsorbent surface charge and the solubility of metal ions. For lead ions, it can be found in four forms according to the $\mathrm{pH}$ of the aqueous solution: $\mathrm{as}_{\mathrm{Pb}^{2+}}$ at $\mathrm{pH}<6.0$, and at a higher $\mathrm{pH}$ as $\mathrm{Pb}(\mathrm{OH})^{+}, \mathrm{Pb}(\mathrm{OH})_{2}$, and $\mathrm{Pb}(\mathrm{OH})^{3-39}$. The lead is permanently present in the $\mathrm{Pb}^{2+}$ ions form at a $\mathrm{pH}$ of $<6.0$, while the other forms are produced at a higher $\mathrm{pH}$. At a $\mathrm{pH}$ of $>7$, the precipitation of lead occurred; thus, the adsorption of lead ions is favored occurred in acidic media ${ }^{40}$. Figure 7 a shows the influence of the $\mathrm{pH}$ on the adsorption of $\mathrm{Pb}^{2+}$ ions onto the surface of the introduced adsorbents. The results shown that $\mathrm{Pb}^{2+}$ ions adsorption onto functionalized ECNFs was highly dependent on the $\mathrm{pH}$ owing to its effect on the ionization of the functional groups linked with the fiber surface. It was found that the functionalized ECNFs exhibited better adsorption capacity with increasing the $\mathrm{pH}$ 


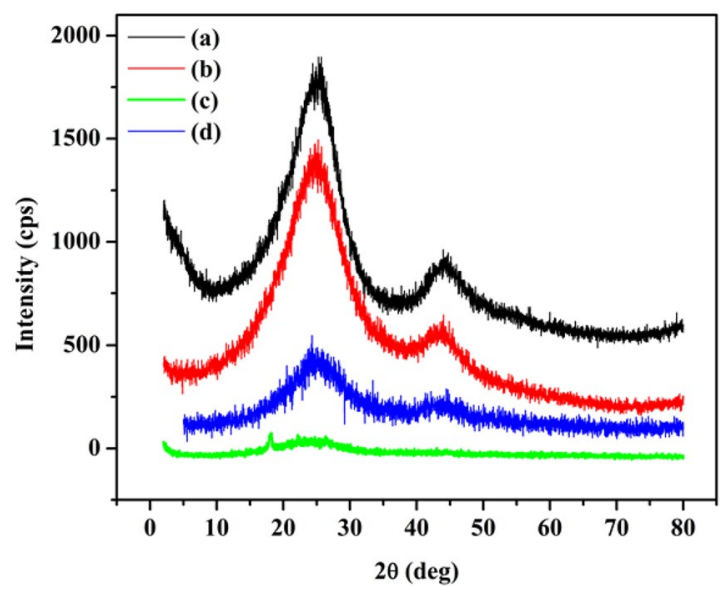

Figure 6. XRD patterns of ECNFs (a), o-ECNFs (b), melam-ECNFs (c) and PmPDA-ECNFs (d).
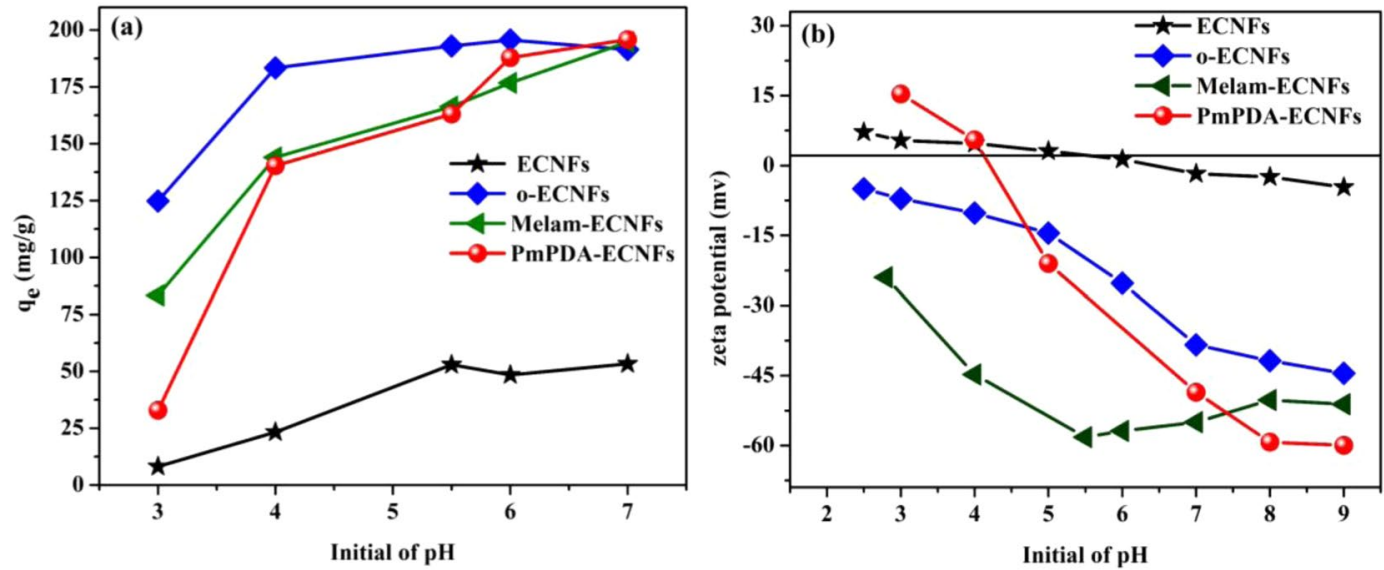

Figure 7. (a) $\mathrm{pH}$ effect on the adsorption of $\mathrm{Pb}^{2+}$ ions onto prepared adsorbents; (b) $\mathrm{pH}$ effect on Zeta potential values.

value, while the pristine ECNFs were only slightly $\mathrm{pH}$-dependent. The optimum $\mathrm{pH}$ value was determined as 5.5 to ensure that $\mathrm{Pb}^{2+}$ ions are not precipitated in solution and this value was used throughout all the adsorption experiments.

To study the charge nature on the pristine and functionalized ECNFs surfaces, the zeta potential was measured at different $\mathrm{pH}$ values ( 3 to 9), as shown in Fig. $7 \mathrm{~b}$. The surfaces of the o-ECNFs and melam-ECNFs were negatively charged in the tested $\mathrm{pH}$ range because of the effects of oxygen and amino functional groups. The PmPDA-ECNFs exhibited different behavior: their surface was positively charged at $\mathrm{pH}<4.2$ and became negatively charged at higher $\mathrm{pH}$ values. At a low $\mathrm{pH}$, the amount of $\mathrm{Pb}^{2+}$ ions adsorbed onto the o-ECNFs and melam-ECNFs was small, despite the negatively charged surfaces, owing to the increasing in the concentration of $\mathrm{H}_{3} \mathrm{O}^{+}$ions, which competed with $\mathrm{Pb}^{2+}$ ions at the adsorption sites. In contrast, the adsorption of $\mathrm{Pb}^{2+}$ ions increased at high $\mathrm{pH}$ was due to the increase of negative charge onto the adsorbent surface and the decrease of $\mathrm{H}_{3} \mathrm{O}^{+}$concentration compared to $\mathrm{Pb}^{2+}$ ions. Hence, the adsorption of $\mathrm{Pb}^{2+}$ ions onto functionalized ECNFs was promoted by the electrostatic interaction between the oxygen and amino groups on their surface and $\mathrm{Pb}^{2+}$ ions at high $\mathrm{pH}$. The difference in the adsorption capacity can be explained by changing the $\mathrm{pH}$ through the following reactions.

$$
\begin{gathered}
-\mathrm{COOH}+\mathrm{H}_{3} \mathrm{O}^{+} \rightarrow-\mathrm{COOH}_{2}^{+}+\mathrm{H}_{2} \mathrm{O} \\
-\mathrm{NH}-+\mathrm{H}_{3} \mathrm{O}^{+} \rightarrow-{ }^{+} \mathrm{NH}_{2}-+\mathrm{H}_{2} \mathrm{O} \\
-\mathrm{COOH}+\mathrm{OH} \rightarrow-\mathrm{COO}^{-}+\mathrm{H}_{2} \mathrm{O} \\
-\mathrm{NH}-+\mathrm{OH} \rightarrow-\mathrm{N}^{-}-+\mathrm{H}_{2} \mathrm{O}
\end{gathered}
$$



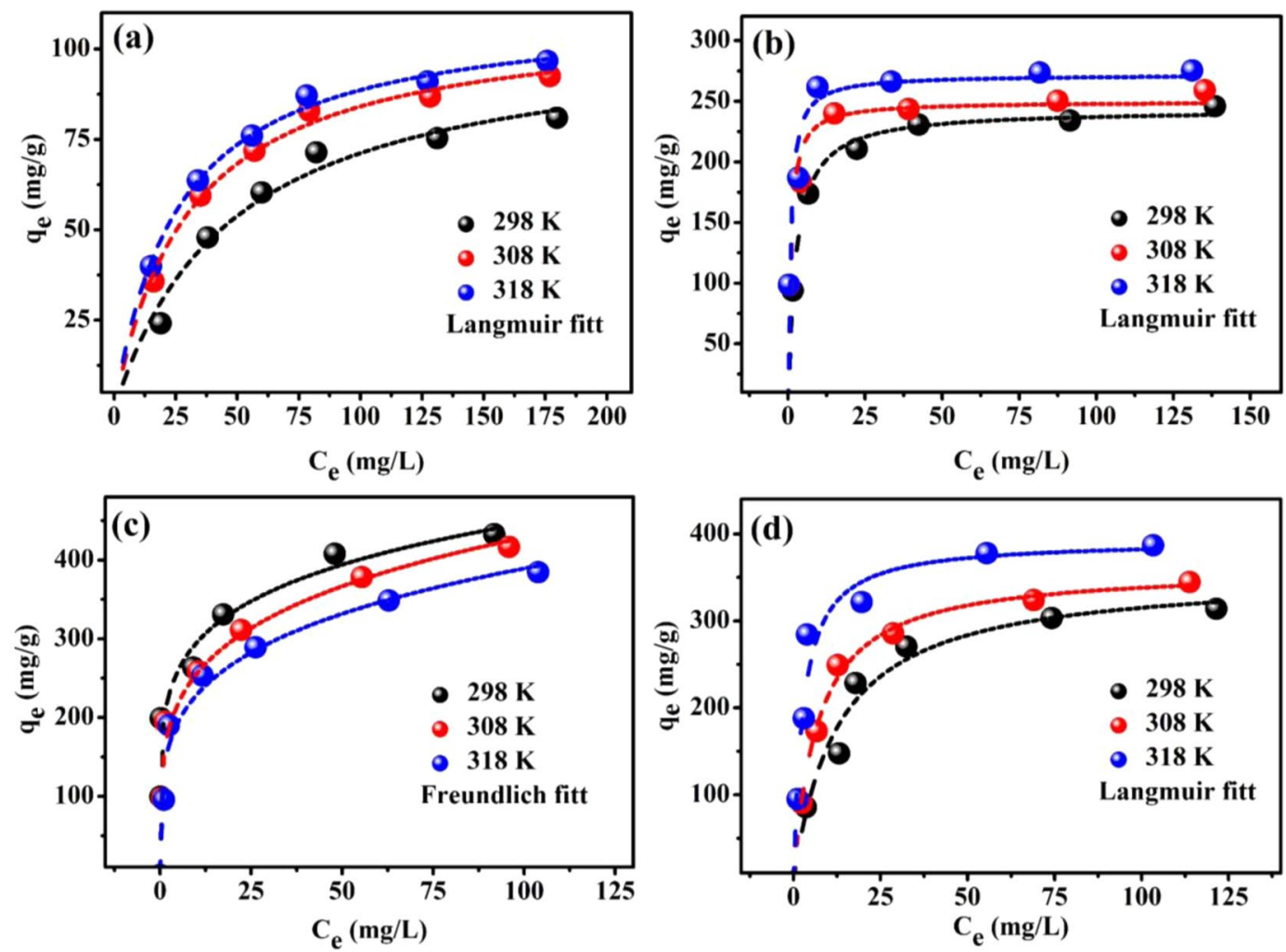

Figure 8. Isotherms for the adsorption of $\mathrm{Pb}^{2+}$ ions onto ECNFs (a), o-ECNFs (b), melam-ECNFs (c) and PmPDA-ECNFs (d).

According to the small quantities of the functionalized ECNFs and their high adsorption capacity at pH values of 5-6, they can be used as effective and suitable adsorbents to remove lead ions from contaminated water.

Isotherm study. Three adsorption models were employed to investigate the adsorption behavior of the pristine and functionalized ECNFs: Langmuir ${ }^{41}$, Freundlich ${ }^{42}$, and Dubinin-Radushkevich $(\mathrm{D}-\mathrm{R})^{43}$. Equations and parameters of all models are shown in Supporting Information (Section I). The nonlinear optimization method was used to reduce the respective error, and the $R^{2}$ and $\chi^{2}$ values were used to identify the best-fit model for the adsorption process. Figures 8 and $\mathrm{S} 1$ show the equilibrium isotherms of $\mathrm{Pb}^{2+}$ ions onto pristine and functionalized ECNFs at various temperatures $\left(298,308\right.$, and $318 \mathrm{~K}$ ). Clearly, the amount of $\mathrm{Pb}^{2+}$ ions adsorbed onto the functionalized ECNFs at equilibrium was significantly higher than that for the pristine ECNFs. This was attributed to functional groups linked with surface of the functionalized ECNFs, which provided sufficient active sites for adsorbing lead ions, reduced the diffusion resistance, and improved dispersibility of functionalized ECNFs. Additionally, the maximum adsorption capacity of $\mathrm{Pb}^{2+}$ ions on all adsorbents was increased with increasing the temperature, except for melam-ECNFs, which favored the adsorption at low temperature. The exothermic nature of adsorption onto surface of melam-ECNFs may be attributed to the presence of a large number of adsorption sites, which is consistent with previous research ${ }^{44}$.

Table 1 presents the parameters of the applied nonlinear isotherm models for analyzing the adsorption process at different temperatures. The maximum monolayer adsorption capacity $(\mathrm{mg} / \mathrm{g})$ of $\mathrm{Pb}^{2+}$ ions onto the introduced adsorbents at $298 \mathrm{~K}$ decreased in the following order: melam-ECNFs (367.5) > PmPDA-ECNFs (354.5) $>$ o-ECNFs (243) > ECNFs (105). As indicated by the high values of $R^{2}$ and low values of $\chi^{2}$, the Langmuir model fitted the experimental data, which was better than the Freundlich and D-R models, except for the experimental data for the melam-ECNFs, which were well fitted by the Freundlich model. This clearly indicates that the adsorption of $\mathrm{Pb}^{2+}$ ions onto the surface of melam-ECNFs was heterogeneous, whereas it was homogeneous for the other adsorbents. The separation factor $\left(R_{L}\right)$ is a useful parameter for predicting the favorability of the adsorption process and is expressed as follows ${ }^{43}$ :

$$
R_{L}=\frac{1}{1+K_{L} C_{o}}
$$

where $C_{o}$ represents the initial concentration $(\mathrm{mg} / \mathrm{L})$, and $K_{L}$ represents the Langmuir constant $(\mathrm{L} / \mathrm{mg})$. Adsorption is favorable when $0<R_{L}<1$ and is irreversible when $R_{L}=0$. The $R_{L}$ values for the adsorption of $\mathrm{Pb}^{2+}$ ions onto all the adsorbents at different temperatures are calculated and plotted, as shown in Fig. 9. The $R_{L}$ valuesranged between 0 and 1.0 for all adsorbents and decreased with increasing the initial concentration of $\mathrm{Pb}^{2+}$ ions. This indicates the favorability of adsorption process in the range of concentrations studied. Furthermore, with the 


\begin{tabular}{|c|c|c|c|c|c|c|c|c|c|c|c|c|c|}
\hline & \multicolumn{4}{|c|}{ Langmuir } & \multicolumn{4}{|c|}{ Freundlich } & \multicolumn{5}{|l|}{ D-R } \\
\hline & $Q_{\text {max }}^{\circ}$ & $K_{L}$ & $R^{2}$ & $\chi^{2}$ & $K_{F}$ & $\mathbf{n}$ & $R^{2}$ & $\chi^{2}$ & $Q_{D R}$ & $K_{D R}$ & $R^{2}$ & $\chi^{2}$ & $E$ \\
\hline \multicolumn{14}{|l|}{$298 \mathrm{~K}$} \\
\hline ECNFs & 05.10 & 0.0210 & 0.9843 & 1.65 & 10.57 & 0.40 & 0.9454 & 5.24 & 76.49 & 87.30 & 0.9712 & 3.17 & 0.0756 \\
\hline o-ECNFs & 243.11 & 0.3919 & 0.9903 & 0.6166 & 116.39 & 0.16 & 0.8425 & 13.12 & 223.75 & 0.5998 & 0.8480 & 9.53 & 0.9130 \\
\hline melam-ECNFs & 367.54 & 3.55 & 0.8666 & 51.04 & 203.76 & 0.17 & 0.9650 & 28.84 & 361.03 & 0.0418 & 0.8593 & 51.74 & 3.46 \\
\hline P $m$ PDA-ECNFs & 54.52 & 0.0799 & 0.9734 & 9.96 & 82.89 & 0.29 & 0.9201 & 30.33 & 312.85 & 20.82 & 0.8910 & 1541.60 & 0.1549 \\
\hline \multicolumn{14}{|l|}{$308 \mathrm{~K}$} \\
\hline ECNFs & 109.51 & 0.0331 & 0.9957 & 0.3640 & 17.98 & 0.32 & 0.9654 & 3.22 & 85.57 & 43.47 & 0.9599 & 3.48 & 0.1072 \\
\hline o-ECNFs & 249.75 & 1.20 & 0.9376 & 5.95 & 144.29 & 0.13 & 0.8300 & 14.98 & 237.29 & 0.0950 & 0.9391 & 12.73 & 2.29 \\
\hline melam-ECNFs & 371.63 & 0.5961 & 0.9254 & 20.82 & 161.67 & 0.21 & 0.9769 & 17.44 & 341.22 & 0.2350 & 0.8696 & 37.15 & 1.45 \\
\hline P $m$ PDA-ECNFs & 361.19 & 0.1463 & 0.9960 & 1.43 & 110.14 & 0.25 & 0.9387 & 27.80 & 303.14 & 2.5200 & 0.9049 & \begin{tabular}{|l|}
80.08 \\
\end{tabular} & 0.4454 \\
\hline \multicolumn{14}{|l|}{$318 \mathrm{~K}$} \\
\hline ECNFs & 111.49 & 0.0387 & 0.9974 & 0.1952 & 21.15 & 0.30 & 0.9707 & 2.72 & 89.02 & 32.46 & 0.9571 & 3.61 & 0.1241 \\
\hline o-ECNFs & 271.88 & 1.26 & 0.9211 & 10.59 & 159.32 & 0.13 & 0.7676 & 25.00 & 255.66 & 0.0722 & 0.7785 & 18.26 & 2.63 \\
\hline melam-ECNFs & 362.23 & 0.3412 & 0.9724 & 10.47 & 140.89 & 0.22 & 0.9719 & 17.50 & 319.04 & 0.4902 & 0.9100 & 33.87 & 1.01 \\
\hline PmPDA-ECNFs & 392.52 & 0.3693 & 0.9597 & 21.12 & 161.54 & 0.20 & 0.8874 & 61.09 & 358.66 & 0.7404 & 0.9466 & 39.95 & 0.8217 \\
\hline
\end{tabular}

Table 1. Adsorption isotherm parameters for $\mathrm{Pb}^{2+}$ ions with pristine and functionalized ECNFs as adsorbents.
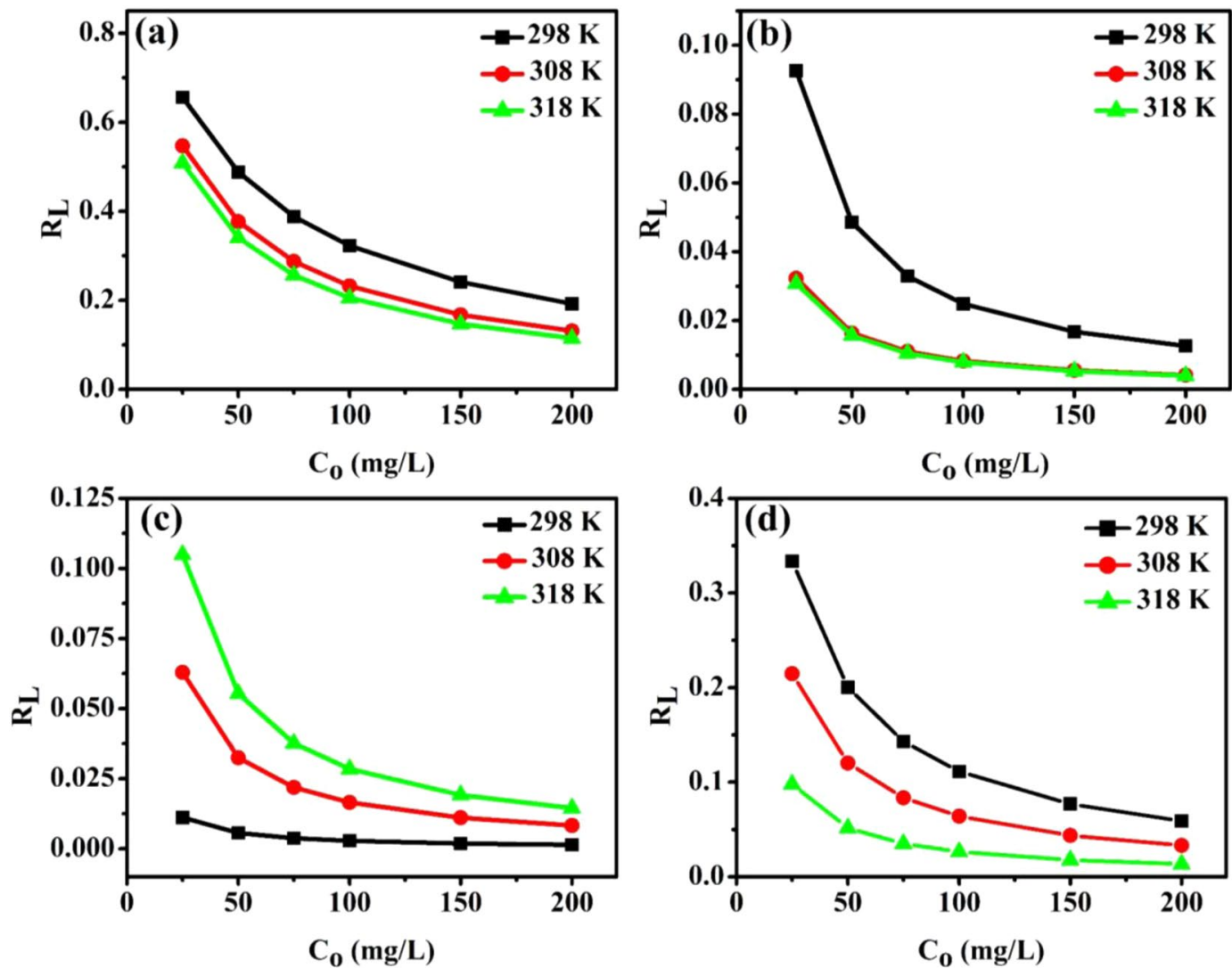

Figure 9. Separation factor $\left(R_{L}\right)$ with respect to the initial concentration of $\mathrm{Pb}^{2+}$ ions on ECNFs (a), o-ECNFs (b), melam-ECNFs (c) and PmPDA-ECNFs (d).

increasing adsorption temperature, the $R_{L}$ value gradually decreased, except for the melam-ECNFs (it increased) which indicates that the adsorption of $\mathrm{Pb}^{2+}$ ions onto the melam-ECNFs was highly favorable at a low adsorption temperature ${ }^{45}$. For the Freundlich model, the values of $n$ were $<1$ for all adsorbents at different temperatures, suggesting that the adsorption was favorable. For D-R model, the calculated $E$ values for the all adsorbents were $<8 \mathrm{~kJ} \cdot \mathrm{mol}^{-1}$, confirming that the adsorption of $\mathrm{Pb}^{2+}$ ions onto the pristine and functionalized ECNFs was physical. The values of $R_{L}, n$, and $E$ indicated that the adsorption of $\mathrm{Pb}^{2+}$ ions onto all adsorbents was favorable. 

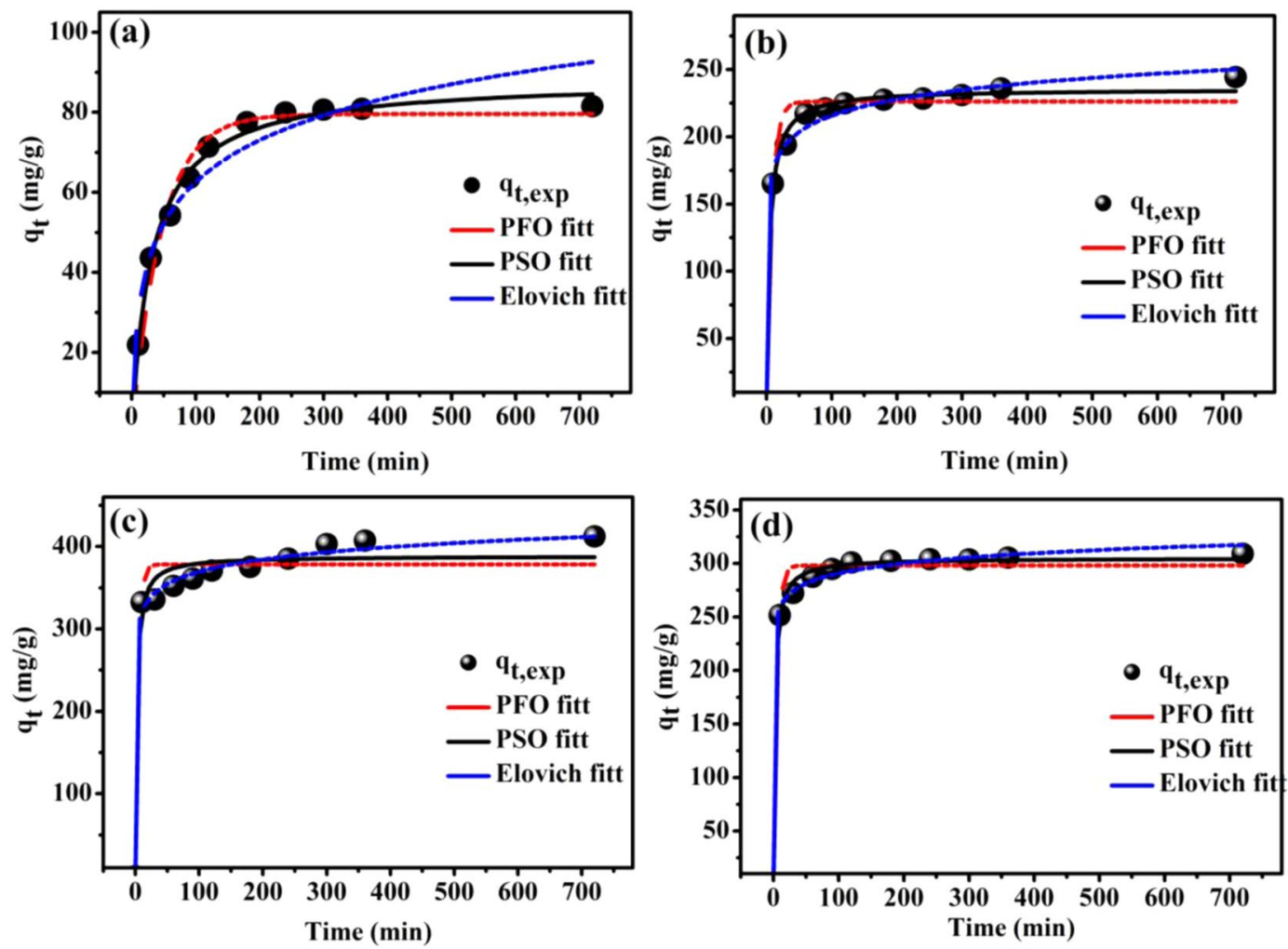

Figure 10. Nonlinear kinetic study of the adsorption of $\mathrm{Pb}^{2+}$ ions onto ECNFs (a), o-ECNFs (b), melamECNFs (c) and PmPDA-ECNFs (d).

Kinetic study. Adsorbents with a high adsorption rate are valuable because they reduce the time required to complete the adsorption process. Therefore, studying the influence of time on the adsorption process is practically important for designing a treatment plant for contaminated water. Figures 10 and S2 show the contact time versus the adsorption capacity of the pristine and functionalized ECNFs. Clearly, the adsorption process was significantly affected by the functionalization process. This phenomenon was due to the presence of functional groups on the surface of the fibers, which enhanced the hydrophilicity of the fiber surface. Therefore, 3.0 and $2.0 \mathrm{~h}$ were required to reach the equilibrium for the adsorption of $\mathrm{Pb}^{2+}$ ions onto the pristine and functionalized ECNFs, respectively. To investigate the adsorption kinetics, three nonlinear models pseudo-first-order (PFO) ${ }^{46}$, pseudo-second-order (PSO) $)^{47}$, and Elovich ${ }^{48}$ were applied. All equations of models and parameters are shown in Supporting Information (Section II). Fig. 10 shows the fitting of the PFO, PSO, and Elovich models, and Table 2 presents the kinetic parameters and the $R^{2}$ and $\chi^{2}$ values obtained via the nonlinear fitting. The $R^{2}$ and $\chi^{2}$ values of the PSO model were higher and lower, respectively, than those of the other models. Moreover, the calculated adsorption capacity values $\left(q_{e, c a l}\right)$ of the PSO model were closer to the experimental results $\left(q_{e, \text { exp }}\right)$ than those of the PFO model. However, according to the $R^{2}(0.995)$ and $\chi^{2}(1.54)$ values, the Elovich model was more appropriate than the other models for describing the adsorption of $\mathrm{Pb}^{2+}$ ions onto the surface of the melam-ECNFs. This indicates that the surface of the melam-ECNFs was heterogeneous and that chemical adsorption may have occurred. In a heterogeneous system, chemisorption, ion exchange, and intraparticle diffusion can occur simultaneously, making it difficult to identify the dominant mechanism. For the Elovich model, $\alpha$ value of the functionalized ECNFs was higher than that of pristine ECNFs, confirming that the adsorption rate was enhanced after surface modification of the ECNFs.

To investigate the adsorption mechanism and identify the rate-determining step, an intraparticle diffusion model was applied, which is expressed as follows:

$$
q_{t}=K_{i d} t^{0.5}+C
$$

where $k_{i d}\left(\mathrm{mg} / \mathrm{g} \mathrm{min}^{1 / 2}\right)$ and $C(\mathrm{mg} / \mathrm{g})$ represent the intraparticle diffusion rate constant and a constant related to the thickness of the boundary layer, respectively, and it can be determined according to the slope and intercept of the $q_{t}$ vs. $t^{0.5}$ plot. All factors of these models were calculated, as shown in Table 2. As shown in Fig. 11, the relationship between $q_{t}$ and $t^{1 / 2}$ is multilinear (two steps) during the adsorption, indicating that the adsorption process is complex and controlled by more than one mechanism. The first step represents the rapid adsorption of $\mathrm{Pb}^{2+}$ ions onto the active sites of the fiber surface, and the second step represents diffusion of $\mathrm{Pb}^{2+}$ ions from the surface to the internal pores. During the first step, most $\mathrm{Pb}^{2+}$ ions were rapidly adsorbed onto the exterior surfaces of the pristine and functionalized ECNFs, and the values of $K_{i d(1)}$ ranged between 4.55 and 11.33, indicating that the mass transfer occurred in the diffusion boundary layer ${ }^{49}$. In the second step, the adsorption was 


\begin{tabular}{|c|c|c|c|c|}
\hline & ECNFs & o-ECNFs & $\begin{array}{l}\text { melam- } \\
\text { ECNFs }\end{array}$ & $\begin{array}{l}\text { PmPDA- } \\
\text { ECNFs }\end{array}$ \\
\hline \multicolumn{5}{|l|}{ PFO } \\
\hline$q_{e, e x p}$ & 81.52 & 244.28 & 412.20 & 309.11 \\
\hline$q_{e, \text { cal }}$ & 79.57 & 226.28 & 378.35 & 298.19 \\
\hline$k_{1}$ & 0.0217 & 0.1195 & 0.2065 & 0.1815 \\
\hline$R^{2}$ & 0.9822 & 0.9705 & 0.9550 & 0.9865 \\
\hline$\chi^{2}$ & 4.18 & 5.85 & 14.36 & 3.31 \\
\hline \multicolumn{5}{|l|}{ PSO } \\
\hline$q_{t, \text { cal }}$ & 88.28 & 235.55 & 388.49 & 305.21 \\
\hline$K_{2}\left(\times 10^{-4}\right)$ & 3.55 & 8.83 & 10.90 & 0.0014 \\
\hline$R^{2}$ & 0.9943 & 0.9941 & 0.9731 & 0.9971 \\
\hline$\chi^{2}$ & 0.5855 & 1.21 & 8.77 & 0.7436 \\
\hline \multicolumn{5}{|l|}{ Elovich } \\
\hline$\alpha$ & 3.66 & 40372.04 & $5.66 * \mathrm{E} 6$ & $2.55 * \mathrm{E} 8$ \\
\hline$\beta$ & 0.0075 & \begin{tabular}{|l|}
0.05727 \\
\end{tabular} & 0.0462 & 0.0735 \\
\hline$R^{2}$ & 0.9583 & 0.99165 & 0.9954 & 0.9963 \\
\hline$\chi^{2}$ & 4.74 & 1.79000 & 1.54 & 0.9294 \\
\hline \multicolumn{5}{|c|}{ Intraparticle diffusion } \\
\hline$K_{i d(1)}$ & 6.13 & 11.33 & 4.55 & 6.28 \\
\hline I & 5.85 & 130.18 & 316.26 & 235.27 \\
\hline$R^{2}$ & 0.9711 & 0.9921 & 0.9671 & 0.9633 \\
\hline$K_{i d(2)}$ & 0.2368 & 1.31 & 0.8774 & 0.4887 \\
\hline$I$ & 75.74 & 209.46 & 388.94 & 295.94 \\
\hline$R^{2}$ & 0.4976 & 0.9734 & 0.7980 & 0.9585 \\
\hline
\end{tabular}

Table 2. Parameters of nonlinear kinetic models for the adsorption of $\mathrm{Pb}^{2+}$ ions onto the pristine and functionalized ECNFs at $298 \mathrm{~K}$.

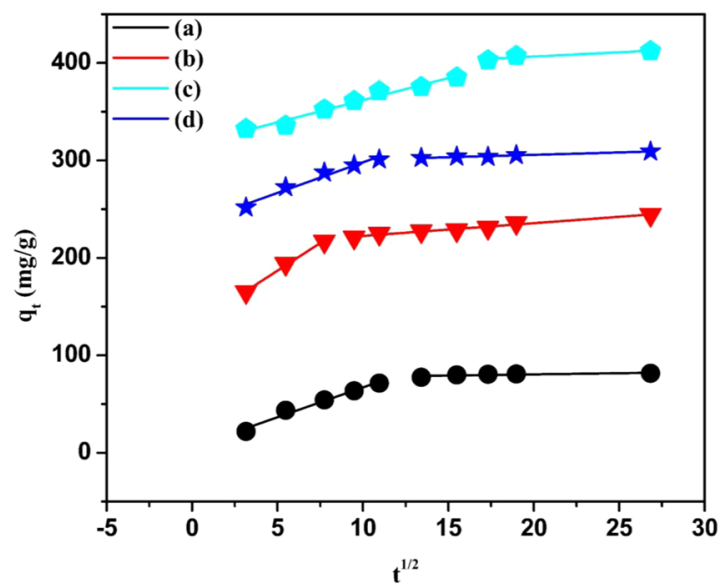

Figure 11. Intraparticle diffusion model for the adsorption of $\mathrm{Pb}^{2+}$ ions onto ECNFs (a), o-ECNFs (b), melamECNFs (c) and PmPDA-ECNFs (d).

gradually, indicating that the intraparticle diffusion process was limited. Additionally, the intraparticle diffusion rate $\left(K_{i d(2)}\right)$ was decreased sharply owing to the minimal pores and lower $\mathrm{Pb}^{2+}$ ions concentration in the solution. Moreover, the $\mathrm{C} i$ value of the pristine ECNFs was lower than that of the functionalized ECNFs, suggesting that the boundary layer in the pristine ECNFs was thinner than that in the functionalized ECNFs. These results confirmed that the functionalization process enhanced the amount of active sites onto the surface of the ECNFs and improved its efficiency in removing $\mathrm{Pb}^{2+}$ ions.

Proposed adsorption mechanism. The adsorption $\mathrm{Pb}^{2+}$ ions onto pristine ECNFs is non-specific binding, while on o-ECNFs, melam-ECNFs and PmPDA-ECNFs is a combined process. Based on the $\mathrm{pH}$ effect, the electrostatic interaction plays vital role in the adsorption process because of the amount of $\mathrm{Pb}^{2+}$ ions was increased by increasing value of $\mathrm{pH}$. This electrostatic interaction may be attributed to the presence of functional groups such as $-\mathrm{COOH},-\mathrm{NH}_{2},=\mathrm{N}$ - and $-\mathrm{OH}$ onto the surface of the functionalized ECNFs leading to increasing of $\mathrm{Pb}^{2+}$ ions adsorption. 


\begin{tabular}{|c|c|c|c|c|c|}
\hline $\mathrm{T}(\mathrm{K})$ & van't Hoff equation & $K_{c}$ & $\Delta G^{\circ}(\mathrm{kJ} / \mathrm{mol})$ & $\Delta H^{\circ}(\mathrm{kJ} / \mathrm{mol})$ & $\Delta S^{\circ}(\mathrm{J} / \mathrm{mol})$ \\
\hline \multicolumn{6}{|c|}{ ECNFs } \\
\hline 298 & \multirow{3}{*}{$\begin{array}{l}y=-1870.93 \mathrm{x}+5.15 \\
R^{2}=0.8656\end{array}$} & 0.3149 & 2.86 & \multirow{3}{*}{15.55} & \multirow{3}{*}{42.84} \\
\hline 308 & & 0.4229 & 2.20 & & \\
\hline 318 & & 0.4665 & 2.01 & & \\
\hline \multicolumn{6}{|c|}{ o-ECNFs } \\
\hline 298 & \multirow{3}{*}{$\begin{array}{l}\mathrm{y}=-3626.66 \mathrm{x}+14.1 \\
R^{2}=0.9463\end{array}$} & 6.6500 & -4.69 & \multirow{3}{*}{30.15} & \multirow{3}{*}{117.23} \\
\hline 308 & & 11.0000 & -6.14 & & \\
\hline 318 & & 14.2600 & -7.03 & & \\
\hline \multicolumn{6}{|c|}{ melam-ECNFs } \\
\hline 298 & \multirow{3}{*}{$\begin{array}{l}y=11118.11 x-32.17 \\
R^{2}=0.8814\end{array}$} & 201.4300 & -13.14 & \multirow{3}{*}{-92.43} & \multirow{3}{*}{-267.44} \\
\hline 308 & & 36.2200 & -9.19 & & \\
\hline 318 & & 19.4900 & -7.85 & & \\
\hline \multicolumn{6}{|c|}{ PmPDA-ECNFs } \\
\hline 298 & \multirow{3}{*}{$\begin{array}{l}\mathrm{y}=-8146.18 \mathrm{x}+28.35 \\
R^{2}=0.9969\end{array}$} & 2.8100 & -2.56 & \multirow{3}{*}{67.73} & \multirow{3}{*}{235.72} \\
\hline 308 & & 6.4500 & -4.77 & & \\
\hline 318 & & 15.7200 & -7.28 & & \\
\hline
\end{tabular}

Table 3. Thermodynamic parameters for the adsorption of $\mathrm{Pb}^{2+}$ ions onto the pristine and functionalized ECNFs.

The low adsorption capacity of pristine ECNFs is also crucial evidence of the role of these functional groups in the adsorption process. In addition, it can consider electrostatic interaction as the main factor here, as the surface charges of the functionalized ECNFs are negative as confirmed by zeta potential measurement. As shown in Fig. 11, the intraparticle diffusion of $\mathrm{Pb}^{2+}$ ions on functionalized ECNFs shows two straight lines without passing through the origin, which would suggest that the rate-limiting step is considered to be a combination of film diffusion and intraparticle mechanisms in the adsorption. In summary, the adsorption mechanism could be attributed to the functional groups on the surface of functionalized ECNFs, which could bind with $\mathrm{Pb}^{2+}$ ions through complexation or electrostatic interaction, while the adsorption mechanism on the surface of pristine ECNFs could be ascribed to nonspecific binding.

Thermodynamic study. For further investigation for the nature of lead adsorption onto the ECNFs, o-ECNFs, ECNFs-melam, and PmPDA-ECNFs, the thermodynamic parameters, such as the standard enthalpy $\left(\Delta H^{\circ}\right)$, Gibbs free energy $\left(\Delta G^{\circ}\right)$, and standard entropy $\left(\Delta S^{\circ}\right)$ were studied and estimated. Thermodynamic Equations are shown in Supporting Information (Section III).

Table 3 presents the values of all thermodynamic parameters. As indicated by the negative values of $\Delta G^{\circ}$, the lead adsorption on the functionalized ECNFs was spontaneous and favorable. In contrast, the lead adsorption onto the pristine ECNFs was nonspontaneous, as indicated by the positive values of $\Delta G^{\circ}$ at different temperatures. The positive values of $\Delta H^{\circ}$ indicate that the adsorption of $\mathrm{Pb}^{2+}$ ions onto the ECNFs, o-ECNFs, and PmPDA-ECNFs was endothermic, whereas with the melam-ECNFs was exothermic (negative values of $\Delta H^{\circ}$ ). This is consistent with our experimental results presented in Table 1, where the adsorption capacity increased with the temperature for all adsorbents except the melam-ECNFs. The positive values of $\Delta S^{\circ}$ indicate random increase at the solid-liquid interface during the adsorption of $\mathrm{Pb}^{2+}$ ions onto all the adsorbents, except for the ECNFs (random decrease). The negative value of $\Delta S^{\circ}$ indicates that the randomness at the solid-liquid interface was reduced during the $\mathrm{Pb}^{2+}$ ions adsorption onto the melam-ECNFs and that the adsorption process occurred without structural changes in the melam-ECNFs ${ }^{50}$.

Table 4 shows the comparison between different carbon materials as adsorbents for the removal of $\mathrm{Pb}^{2+}$ ions. According to the maximum adsorption capacity and the required time to equilibrium, functionalized ECNFs are a better nanoadsorbent for $\mathrm{Pb}^{2+}$ ions removal than most reported carbon nanomaterials.

\section{Conclusion}

Electrospun carbon nanofibers (ECNFs) can be fabricated via electrospinning followed by carbonization process. ECNFs showed superior over other carbon nanomaterials where their properties can be controlled during carbonization process. Moreover, their high surface area-to-volume, small fiber diameters and porosity, make them an attractive for various applications. The efficiency of ECNFs can be improved via surface modification to increase its hydrophilicity and hence their efficiency in removing heavy metals such as $\mathrm{Pb}^{2+}$ ions. Routine analysis confirmed the successful surface modification with melamine and $\mathrm{PmPDA}$. The adsorption of $\mathrm{Pb}^{2+}$ ions onto the as-prepared materials, o-ECNFs, PmPDA-ECNFs, and Melam-ECNFs, is $\mathrm{pH}$ dependent and was better than onto pristine ECNFs. The maximum adsorption capacities $\left(Q^{\circ}{ }_{\text {max }}\right)$ of the ECNFs, o-ECNFs, PmPDA-ECNFs, and melam-ECNFs were 105, 243, 354, and $367 \mathrm{mg} / \mathrm{g}$, respectively. Experimental data for the isotherms and kinetics fitted well with Langmuir isotherm model and PSO model, respectively. According to thermodynamic studies, the adsorption of $\mathrm{Pb}^{2+}$ ions onto functionalized ECNFs was spontaneous and endothermic, except with melam-ECNFs was exothermic process. The adsorption mechanism could be attributed to the functional groups on the surface of functionalized ECNFs, which could bind with $\mathrm{Pb}^{2+}$ ions through complexation or electrostatic 


\begin{tabular}{|l|l|l|l|}
\hline Adsorbent & $\begin{array}{l}\text { Adsorption capacity } \\
\boldsymbol{q}_{\max }(\mathbf{m g} / \mathbf{g})\end{array}$ & Condition & Ref. \\
\hline CNTs & 102 & $\mathrm{pH} 5$, time $=80 \mathrm{~min}$ & 51 \\
\hline MWCNTs@SiO ${ }_{2}-\mathrm{NH}_{2}$ & 147 & $\mathrm{pH} 7, C_{o}=250 \mathrm{mg} / \mathrm{L}, \mathrm{T}=30^{\circ} \mathrm{C}$, time $=24 \mathrm{~h}$ & 52 \\
\hline Oxidized $\mathrm{MWCNTs}$ & 117.64 & $\mathrm{pH} 7, C_{o}=1200 \mathrm{mg} / \mathrm{L}, \mathrm{T}=25^{\circ} \mathrm{C}$ & 53 \\
\hline CNF-CoFe $\mathrm{O}_{4}$ & 42.9 & $\mathrm{pH} 4, C_{o}=100 \mathrm{mg} / \mathrm{L}, \mathrm{T}=25^{\circ} \mathrm{C}$, time $=180 \mathrm{~min}$ & 54 \\
\hline GO aerogels & 158.7 & $\mathrm{pH} 5.5, C_{o}=100 \mathrm{mg} / \mathrm{L}$, & 55 \\
\hline magnetic chitosan@GO & 76.94 & $\mathrm{pH} 5, \mathrm{~T}=30^{\circ} \mathrm{C}$ & 56 \\
\hline GO/L-Trp & 222 & $\mathrm{pH} 4, C_{o}=250 \mathrm{mg} / \mathrm{L}, \mathrm{T}=20^{\circ} \mathrm{C}$, time $=40 \mathrm{~min}$ & 57 \\
\hline ECNFs & 105 & $\mathrm{pH} 5.5, C_{o}=200 \mathrm{mg} / \mathrm{L}, \mathrm{T}=25^{\circ} \mathrm{C}$, time $=180 \mathrm{~min}$ & This work \\
\hline oxidized ECNFs & 243 & $\mathrm{pH} 5.5, C_{o}=200 \mathrm{mg} / \mathrm{L}, \mathrm{T}=25^{\circ} \mathrm{C}$, time $=60 \mathrm{~min}$ & This work \\
\hline melam-ECNFs & 367.5 & $\mathrm{pH} 5.5, C_{o}=200 \mathrm{mg} / \mathrm{L}, \mathrm{T}=25^{\circ} \mathrm{C}$, time $=60 \mathrm{~min}$ & This work \\
\hline PmPDA-ECNFs & 354.5 & $\mathrm{pH} 5.5, C_{o}=200 \mathrm{mg} / \mathrm{L}, \mathrm{T}=25^{\circ} \mathrm{C}$, time $=60 \mathrm{~min}$ & This work \\
\hline
\end{tabular}

Table 4. A comparison of the adsorption capacity of functionalized ECNFs with the other carbon nanomaterials.

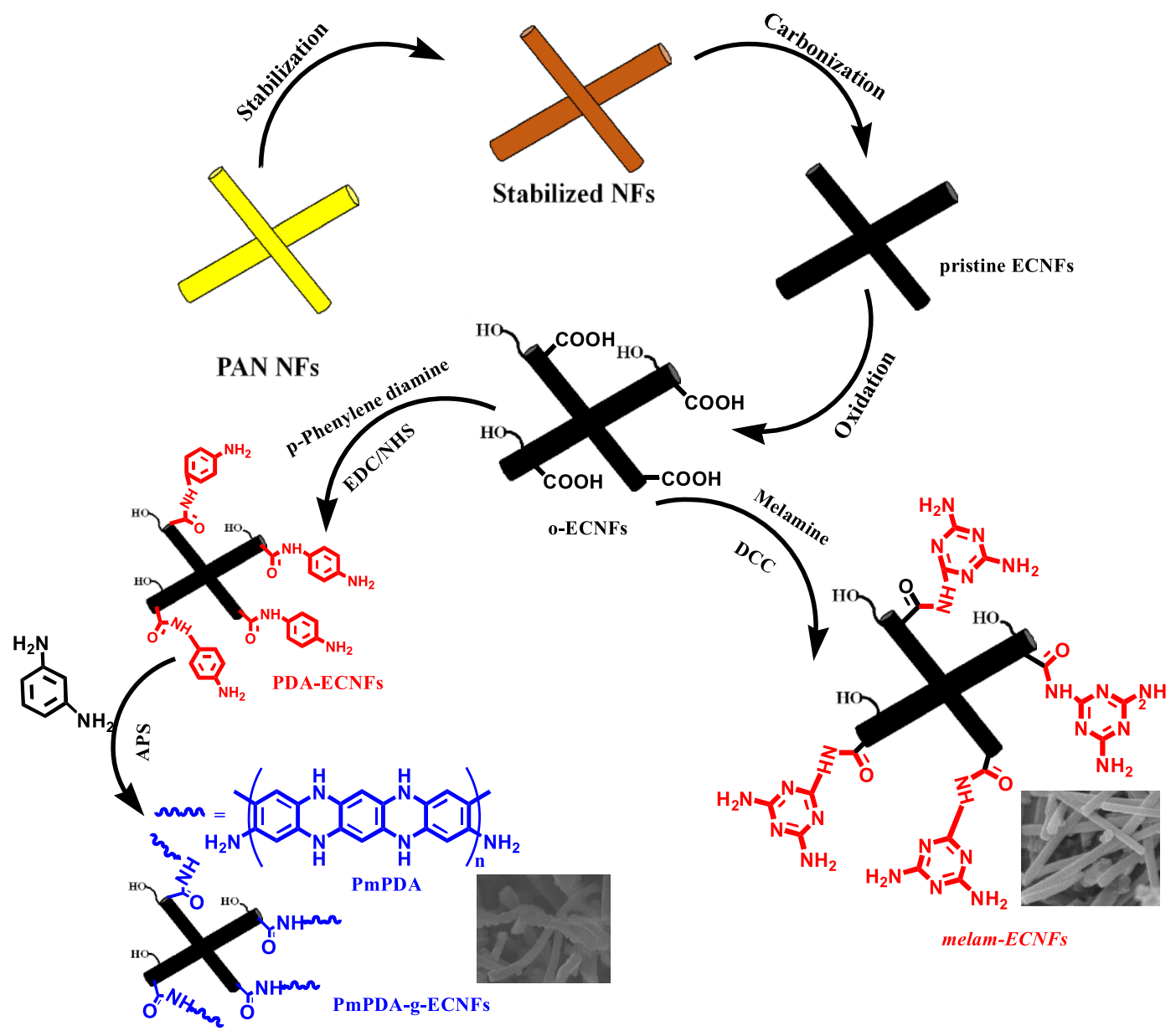

Scheme 1. Fabrication steps of pristine and functionalized ECNFs.

interaction, while the adsorption mechanism on the surface of pristine ECNFs could be ascribed to nonspecific binding. Overall, the surface modification of the ECNFs successfully enhanced the adsorption capacity and the adsorption rate of $\mathrm{Pb}^{2+}$ ions from aqueous solutions.

\section{Experimental Methods}

Materials and reagents. $\quad N, N^{\prime}$-dicyclohexylcarbodiimide (DCC), polyacrylonitrile (PAN), lead nitrate $\left(\mathrm{Pb}\left(\mathrm{NO}_{3}\right)_{2}\right), m$-phenylene diamine, and melamine were provided from Sigma-Aldrich. $N, N$-dimethyl formamide (DMF) and hydrochloric acid were purchased from Panreac AppliChem. Nitric acid and sodium hydroxide were purchased from Global Chemical Ltd. Dimethyl sulfoxide (DMSO) was purchased from bio-Basic INC. 
$N$-hydroxysuccinimide (NHS) and $N$-(3-(dimethylamino)propyl)- $N$ '-ethylcarbodiimide hydrochloride (EDC) were purchased from TCI (Tokyo, Japan). All chemicals were used without purification.

Synthesis of adsorbents. ECNFs were prepared using electrospinning followed by carbonization, as described by Thamer et al. ${ }^{27}$. In a typical way, PAN $(1 \mathrm{~g})$ was dissolved in DMF $(9 \mathrm{~mL})$ with stirring at room temperature for $12 \mathrm{~h}$. Then, the mixture was transferred to a syringe and electrospinning take place under the following conditions; an applied voltage of $16 \mathrm{kV}$; tip-to-collector distance (TCD) was $15 \mathrm{~cm}$, and the humidity was $>30 \%$. PAN nanofibers were deposited on polyethylene paper on a drum collector and then the mat was removed and dried at $80^{\circ} \mathrm{C}$ under vacuum for $12 \mathrm{~h}$. PAN nanofibers were stabilized at $280^{\circ} \mathrm{C}$ for $2 \mathrm{~h}$ under air followed by carbonization at $800^{\circ} \mathrm{C}$ for $1.0 \mathrm{~h}$ under inert gas (nitrogen) with a heating rate of $5^{\circ} \mathrm{C} / \mathrm{min}$.

Oxidized ECNFs (o-ECNFs) and poly ( $m$-phenylene diamine)- $g$-ECNFs (P $m$ PDA-ECNFs) were prepared according the procedure described elsewhere ${ }^{29}$ as shown in Scheme 1.

Melamine was grafted onto ECNFs via amidation reaction, as follows: o-ECNFs (250 mg) were dispersed in DMSO $(50 \mathrm{~mL})$ via sonication for $15 \mathrm{~min}$. Then, the mixture was cooled in an ice bath, followed by addition of DCC $(0.5 \mathrm{~g})$ with stirring for $1 \mathrm{~h}$. Melamine was added to the mixture, with stirring at room temperature for $48 \mathrm{~h}$. The solid product (melam-ECNFs) was filtrated, washed several times with hot ethanol and dried at $70^{\circ} \mathrm{C}$ under vacuum overnight as shown in Scheme 1.

Characterization of adsorbents. The chemical structure and surface modification of the ECNFs was confirmed using diverse techniques, such as Fourier transform infrared (FT-IR) spectroscopy (Optic Tensor 27, Bruker, Germany), thermogravimetric analysis (TGA) (Q500, TA, USA), X-ray photoelectron spectroscopy (XPS, $\mathrm{Al} K_{\alpha} \mathrm{X}$-ray,Thermo Scientific) and X-ray diffraction (XRD) measurements (MiniFlex) with Cu $K_{\alpha}$ radiation $(\lambda=1.5418 \AA)$. The morphology of all the adsorbents was analyzed via field-emission scanning electron microscopy (FE-SEM, JEOL2100F). The nature of the surface charge was determined using a NanoPlus zeta/nanoparticle analyzer.

Adsorption experiments. The initial $\mathrm{Pb}^{2+}$ ions concentrations varied from 25 to $200 \mathrm{mg} / \mathrm{L}$, prepared from a stock solution of $1000 \mathrm{mg} / \mathrm{L}$, and the $\mathrm{pH}$ value of all the $\mathrm{Pb}^{2+}$ ions solutions was maintained at 5.5.

For adsorption isotherm analysis, the adsorption study was conducted by adding $3 \mathrm{mg}$ of adsorbent to $12 \mathrm{~mL}$ of lead ion $\left(\mathrm{Pb}^{2+}\right)$ solution (in a polypropylene tube) at 25,35 , and $45^{\circ} \mathrm{C}$. After the adsorbent was added, the tube containing the solution was shaken for $4 \mathrm{~h}$. The samples were filtered through a $0.4-\mu \mathrm{m}$ membrane filter, and the residual concentrations of $\mathrm{Pb}^{2+}$ ions in the filtrates were determined using atomic absorption spectrometer (PerkinElmer, USA) at a wavelength of $283.3 \mathrm{~nm}$. The effect of the $\mathrm{pH}$ on the $\mathrm{Pb}^{2+}$ ions removal by the adsorbents was investigated at $\mathrm{pH}$ values ranging from 3 to 7 , which can be adjusted by adding $\mathrm{NaOH}$ or $\mathrm{HNO}_{3}$ and measured using a $\mathrm{pH}$ meter (3510-Jenway). Mixtures of $3 \mathrm{mg}$ of adsorbent and $12 \mathrm{~mL} \mathrm{of} \mathrm{Pb}^{2+}$ ions $(100 \mathrm{mg} / \mathrm{L})$ with different $\mathrm{pH}$ values were shaken at $70 \mathrm{rpm}$ and $25^{\circ} \mathrm{C}$ for $24 \mathrm{~h}$.

To determine the equilibrium contact time, a $200-\mathrm{mg} / \mathrm{L}$ solution of $\mathrm{Pb}^{2+}$ ions was exposed to the adsorbents as previously mentioned, and samples were removed at various times (from 10 to $720 \mathrm{~min}$ ). Then, the mixture was filtered through a $0.4-\mu \mathrm{m}$-pore size membrane. The amounts of adsorbed $\mathrm{Pb}^{2+}$ ions at equilibrium $\left(q_{e}, \mathrm{mg} / \mathrm{L}\right)$ at time $t\left(\mathrm{q}_{\mathrm{t}}, \mathrm{mg} / \mathrm{L}\right)$ were calculated using the following equations:

$$
\begin{aligned}
& q_{e}=\frac{C_{o}-C_{e}}{m} \times V \\
& q_{t}=\frac{C_{o}-C_{t}}{m} \times V
\end{aligned}
$$

where $C_{o}(\mathrm{mg} / \mathrm{L})$ represents the initial concentration of $\mathrm{Pb}^{2+}$ ions, $C_{e}(\mathrm{mg} / \mathrm{L})$ represents the equilibrium concentration in the solution, $V(\mathrm{~L})$ represents the volume of the solution, and $m(\mathrm{~g})$ represents the adsorbent mass.

Received: 3 September 2019; Accepted: 27 November 2019;

Published online: 19 December 2019

\section{References}

1. Kadirvelu, K., Thamaraiselvi, K. \& Namasivayam, C. Removal of heavy metals from industrial wastewaters by adsorption onto activated carbon prepared from an agricultural solid waste. Bioresour. Technol. 76, 63-65 (2001).

2. Jaishankar, M., Tseten, T., Anbalagan, N., Mathew, B. B. \& Beeregowda, K. N. Toxicity, mechanism and health effects of some heavy metals. Interdiscip. Toxicol. 7, 60-72 (2014).

3. US Environmental Protection Agency (US EPA). Ground water and drinking water: Basic information about lead in drinking water. Available at: https://www.epa.gov/ground-water-and-drinking-water/basic-information-about-lead-drinking-water. (Accessed: 19th October 2019).

4. Fiyadh, S. S. et al. Review on heavy metal adsorption processes by carbon nanotubes. J. Clean. Prod. 230, 783-793 (2019).

5. Xu, D., Tan, X., Chen, C. \& Wang, X. Removal of $\mathrm{Pb}$ (II) from aqueous solution by oxidized multiwalled carbon nanotubes. J. Hazard. Mater. 154, 407-416 (2008).

6. Rao, G. P., Lu, C. \& Su, F. Sorption of divalent metal ions from aqueous solution by carbon nanotubes: A review. Sep. Purif. Technol. 58, 224-231 (2007).

7. Pham, Q. P., Sharma, U. \& Mikos, A. G. Electrospinning of Polymeric Nanofibers for Tissue Engineering Applications: A Review. Tissue Eng. 12, 1197-1211 (2006).

8. Deravi, L. F. et al. Design and Fabrication of Fibrous Nanomaterials Using Pull Spinning. Macromol. Mater. Eng. 302, 1600404 (2017). 
9. Thamer, B. M. et al. Cobalt-incorporated, nitrogen-doped carbon nanofibers as effective non-precious catalyst for methanol electrooxidation in alkaline medium. Appl. Catal. A Gen. 498, 230-240 (2015).

10. Thamer, B. M. et al. Influence of Nitrogen doping on the Catalytic Activity of Ni-incorporated Carbon Nanofibers for Alkaline Direct Methanol Fuel Cells. Electrochim. Acta 142, 228-239 (2014).

11. Yoon, K., Hsiao, B. S. \& Chu, B. Functional nanofibers for environmental applications. J. Mater. Chem. 18, 5326 (2008).

12. Bognitzki, M. et al. Nanostructured Fibers via Electrospinning. Adv. Mater. 13, 70-72 (2001).

13. Bhardwaj, N. \& Kundu, S. C. Electrospinning: A fascinating fiber fabrication technique. Biotechnol. Adv. 28, 325-347 (2010).

14. Li, D. \& Xia, Y. Electrospinning of Nanofibers: Reinventing the Wheel? Adv. Mater. 16, 1151-1170 (2004).

15. Shim, W. G. et al. Adsorption characteristics of benzene on electrospun-derived porous carbon nanofibers. J. Appl. Polym. Sci. 102, 2454-2462 (2006).

16. Oh, G. Y. et al. Adsorption of toluene on carbon nanofibers prepared by electrospinning. Sci. Total Environ. 393, 341-347 (2008).

17. Bai, Y., Huang, Z.-H. \& Kang, F. Surface oxidation of activated electrospun carbon nanofibers and their adsorption performance for benzene, butanone and ethanol. Colloids Surfaces A Physicochem. Eng. Asp. 443, 66-71 (2014).

18. Bai, Y., Huang, Z.-H., Zhang, Z.-X. \& Kang, F. Improvement of the hydrophilicity of electrospun porous carbon nanofibers by grafting phenylsulfonic acid groups. J. Colloid Interface Sci. 394, 177-182 (2013).

19. Mirzaei, E. et al. Functionalization of PAN-Based Electrospun Carbon Nanofibers by Acid Oxidation: Study of Structural,Electrical and Mechanical Properties. Fullerenes, Nanotub. Carbon Nanostructures 23, 930-937 (2015).

20. Teng, M., Qiao, J., Li, F. \& Bera, P. K. Electrospun mesoporous carbon nanofibers produced from phenolic resin and their use in the adsorption of large dye molecules. Carbon N. Y. 50, 2877-2886 (2012).

21. Li, X. et al. Adsorption of ciprofloxacin, bisphenol and 2-chlorophenol on electrospun carbon nanofibers: In comparison with powder activated carbon. J. Colloid Interface Sci. 447, 120-127 (2015).

22. Lai, C.-C. \& Lo, C.-T. Plasma oxidation of electrospun carbon nanofibers as supercapacitor electrodes. RSC Adv. 5, 38868-38872 (2015).

23. Lai, C.-C., Chung, M.-Y. \& Lo, C.-T. Nitric acid oxidation of electrospun carbon nanofibers as supercapacitor electrodes. Text. Res. J. 87, 2337-2348 (2017)

24. Hu, H., Zhang, T., Yuan, S. \& Tang, S. Functionalization of multi-walled carbon nanotubes with phenylenediamine for enhanced CO2 adsorption. Adsorption 23, 73-85 (2017).

25. Shao, D., Jiang, Z., Wang, X., Li, J. \& Meng, Y. Plasma Induced Grafting Carboxymethyl Cellulose on Multiwalled Carbon Nanotubes for the Removal of $\mathrm{UO}_{2}{ }^{2+}$ from Aqueous Solution. J. Phys. Chem. B 113, 860-864 (2009).

26. Li, Z., Chen, J. \& Ge, Y. Removal of lead ion and oil droplet from aqueous solution by lignin-grafted carbon nanotubes. Chem. Eng. J 308, 809-817 (2017).

27. Thamer, B. M., El-hamshary, H., Al-deyab, S. S. \& El-newehy, M. H. Functionalized electrospun carbon nanofibers for removal of cationic dye. Arab. J. Chem. https://doi.org/10.1016/j.arabjc.2018.07.020 (2018).

28. Thamer, B. M. et al. Alkali-activated electrospun carbon nanofibers as an efficient bifunctional adsorbent for cationic and anionic dyes. Colloids Surfaces A Physicochem. Eng. Asp. 582, 123835 (2019).

29. Thamer, B. M. et al. Effective adsorption of Coomassie brilliant blue dye using poly(phenylene diamine)grafted electrospun carbon nanofibers as a novel adsorbent. Mater. Chem. Phys. 234, 133-145 (2019).

30. Yang, G.-X. \& Jiang, H. Amino modification of biochar for enhanced adsorption of copper ions from synthetic wastewater. Water Res. 48, 396-405 (2014).

31. Anbia, M. \& Haqshenas, M. Adsorption studies of $\mathrm{Pb}(\mathrm{II})$ and $\mathrm{Cu}(\mathrm{II})$ ions on mesoporous carbon nitride functionalized with melamine-based dendrimer amine. Int. J. Environ. Sci. Technol. 12, 2649-2664 (2015).

32. Min, Y. L., Wang, T., Zhang, Y. G. \& Chen, Y. C. The synthesis of poly(p-phenylenediamine) microstructures without oxidant and their effective adsorption of lead ions. J. Mater. Chem. 21, 6683-6689 (2011).

33. Vuković, G. D. et al. Removal of lead from water by amino modified multi-walled carbon nanotubes. Chem. Eng. J. 173, 855-865 (2011).

34. Kumar, N. A. et al. Polyaniline-grafted reduced graphene oxide for efficient electrochemical supercapacitors. ACS Nano 6, $1715-1723(2012)$

35. Chowdhury, F. A. et al Graphene oxide/carbon nanoparticle thin film based IR detector: Surface properties and device characterization. AIP Adv. 5 (2015).

36. Dementjev, A. P. et al. X-ray photoelectron spectroscopy reference data for identification of the C3N4 phase in carbon-nitrogen films. Diam. Relat. Mater. 9, 1904-1907 (2000).

37. Muñoz-Sandoval, E., Fajardo-Díaz, J. L., Sánchez-Salas, R., Cortés-López, A. J. \& López-Urías, F. Two Sprayer CVD Synthesis of Nitrogen-doped Carbon Sponge-type Nanomaterials. Sci. Rep. 8 (2018).

38. Kundu, S. K. \& Bhaumik, A. A triazine-based porous organic polymer: a novel heterogeneous basic organocatalyst for facile one-pot synthesis of 2-amino- $4 \mathrm{H}$-chromenes. RSC Adv 5, 32730-32739 (2015).

39. Weng, C.-H. Modeling Pb(II) adsorption onto sandy loam soil. J. Colloid Interface Sci. 272, 262-270 (2004).

40. Li, Y. H. et al. Lead adsorption on carbon nanotubes. Chem. Phys. Lett. 357, 263-266 (2002).

41. Langmuir. The adsorption of gases on plane surfaces of glass, mica and platinum. J. Am. Chem. Soc. 40, 1361-1403 (1918).

42. Freundlich, H. Über die adsorption in lösungen. Zeitschrift für Phys. Chemie 57, 385-470 (1907).

43. Dubinin, M. M. \& L. V. R. Equation of the characteristic curve of activated charcoal. Chem. Zentr 1, 857 (1947).

44. Shahbazi, A., Younesi, H. \& Badiei, A. Functionalized SBA-15 mesoporous silica by melamine-based dendrimer amines for adsorptive characteristics of $\mathrm{Pb}(\mathrm{II}), \mathrm{Cu}(\mathrm{II})$ and $\mathrm{Cd}(\mathrm{II})$ heavy metal ions in batch and fixed bed column. Chem. Eng. J 168, 505-518 (2011).

45. Lv, L. et al. Enhanced adsorption of $\mathrm{Cu}(\mathrm{ii})$ ions on chitosan microspheres functionalized with polyethylenimine-conjugated poly(glycidyl methacrylate) brushes. RSC Adv 6, 78136-78150 (2016).

46. Lagergren, S. About the theory of so-called adsorption of soluble substances. K. Sven. Vetenskapsakademiens Handl 24, 1-39 (1898).

47. Blanchard, G. M. \& Maunaye, G. M. Removal of heavy metals from waters by means of natural zeolites. Water Res 18, 1501-1507 (1984).

48. Roginsky, S. \& Y. B. Z. The catalytic oxidation of carbon monoxide on manganese dioxide. Acta Phys. Chem. USSR 1, 554 (1934).

49. Zhong, Z. et al. Enhanced phosphate sequestration by Fe(iii) modified biochar derived from coconut shell. RSC Adv 9, 10425-10436 (2019).

50. Sarı, A., Tuzen, M., Uluözlü, Ö. D. \& Soylak, M. Biosorption of $\mathrm{Pb}(\mathrm{II})$ and $\mathrm{Ni}(\mathrm{II})$ from aqueous solution by lichen (Cladonia furcata) biomass. Biochem. Eng. J. 37, 151-158 (2007).

51. Kabbashi, N. A. et al. Kinetic adsorption of application of carbon nanotubes for $\mathrm{Pb}(\mathrm{II})$ removal from aqueous solution. J. Environ. Sci. 21, 539-544 (2009).

52. Yang, K. et al. Multiwalled carbon nanotubes incorporated with or without amino groups for aqueous $\mathrm{Pb}(\mathrm{II})$ removal: Comparison and mechanism study. J. Mol. Liq. 260, 149-158 (2018)

53. Tofighy, M. A. \& Mohammadi, T. Adsorption of divalent heavy metal ions from water using carbon nanotube sheets. J. Hazard. Mater. 185, 140-147 (2011)

54. Santhosh, C. et al. Removal of cationic and anionic heavy metals from water by $1 \mathrm{D}$ and 2D-carbon structures decorated with magnetic nanoparticles. Sci. Rep. 7 (2017). 
55. Tabrizi, N. S. \& Zamani, S. Removal of Pb(II) from aqueous solutions by graphene oxide aerogels. Water Sci. Technol. 74, 256-265 (2016).

56. Fan, L., Luo, C., Sun, M., Li, X. \& Qiu, H. Highly selective adsorption of lead ions by water-dispersible magnetic chitosan/graphene oxide composites. Colloids Surfaces B Biointerfaces 103, 523-529 (2013).

57. Tan, M., Liu, X., Li, W. \& Li, H. Enhancing Sorption Capacities for Copper(II) and Lead(II) under Weakly Acidic Conditions by 1 -Tryptophan-Functionalized Graphene Oxide. J. Chem. Eng. Data 60, 1469-1475 (2015).

\section{Acknowledgements}

The authors thank the RSSU at King Saud University for their technical support. This work was supported by the Deanship of Scientific Research through the initiative of DSR Graduate Students Research Support (GSRS).

\section{Author contributions}

B.M.T., M.H.N. and A.A. proposed the idea, designed the study and discussed the data with A.M.A. and H.E. and M.M.A. Conducted all experiments and analyses.by B.M.T. and M.H.E. wrote the manuscript.

\section{Competing interests}

The authors declare no competing interests.

\section{Additional information}

Supplementary information is available for this paper at https://doi.org/10.1038/s41598-019-55679-6.

Correspondence and requests for materials should be addressed to M.H.E.-N.

Reprints and permissions information is available at www.nature.com/reprints.

Publisher's note Springer Nature remains neutral with regard to jurisdictional claims in published maps and institutional affiliations.

(c) (i) Open Access This article is licensed under a Creative Commons Attribution 4.0 International License, which permits use, sharing, adaptation, distribution and reproduction in any medium or format, as long as you give appropriate credit to the original author(s) and the source, provide a link to the Creative Commons license, and indicate if changes were made. The images or other third party material in this article are included in the article's Creative Commons license, unless indicated otherwise in a credit line to the material. If material is not included in the article's Creative Commons license and your intended use is not permitted by statutory regulation or exceeds the permitted use, you will need to obtain permission directly from the copyright holder. To view a copy of this license, visit http://creativecommons.org/licenses/by/4.0/.

(C) The Author(s) 2019 